\title{
硅杂环戊二烯并苯有机小分子化合物研究进展
}

\author{
曲红梅* 蒋丽丽陈 涛唐建可 \\ (天津大学化工学院 系统生物工程教育部重点实验室 天津市生物制药工程重点实验室 天津 300072)
}

\begin{abstract}
摘要 硅杂环戊二烯并苯有机小分子结构的特殊性, 赋予其独特的光电特性, 在有机光电功能材料等领域具有广阔的 应用前景. 其中, 并苯的刚性共平面结构可避免构象无序性、扩大 $\pi$-共轭; 硅杂环戊二烯能够形成 $\sigma^{*}-\pi^{*}$ 共轭，可有效 降低体系 LUMO 能级、提高电子亲合势. 硅杂环戌二烯并苯有机小分子主要包括苯并噻咯、硅桥联对二苯乙烯衍生物、 二苯并噻咯和双硅桥联对一三联苯等. 综述了硅杂环戊二烯并苯小分子的合成方法、结构修饰、性能及应用的研究进展, 并对今后的研究方向进行了展望.
\end{abstract}

关键词 硅杂环戊二烯并苯; 硅桥联; $\pi$-共轭; 光电材料

\section{Research Progress in Benzosilole-Containing Organic Compounds}

\author{
Qu, Hongmei* Jiang, Lili Chen, Tao Tang, Jianke
}

(Key Laboratory of Systems Bioengineering, Ministry of Education, Tianjin Key Laboratory of Biological and

Pharmaceutical Engineering, School of Chemical Engineering and Technology, Tianjin University, Tianjin 300072)

\begin{abstract}
Benzosilole-containing organic molecules have been potentially applied in opto-electronic material fields, due to their unique structural and optical characteristics. The rigid planar structures of acenes prevent conformational disorder, and extend the $\pi$-conjugation. Silacyclopentadiene can form $\sigma^{*}-\pi^{*}$ conjugation, lowering the LUMO and enhancing the electron affinity efficiently. In this review, benzosiloles, silicon-bridged stilbene derivatives, silafluorenes and bis-silicon-bridged $p$-terphenyls are focused on. The recent research progress in the synthesis, modification, properties and applications of benzosilole-containing organic compounds is summarized, and the future research of this field is also prospected.
\end{abstract}

Keywords benzosilole; silicon-bridge; $\pi$-conjugated; opto-electronic materials

有机 $\pi$-共轭化合物可以作为光电功能材料, 用于制 作有机场效应晶体管 $(\mathrm{OFET})^{[1 \sim 4]}$ 、有机发光二极管 $(\mathrm{OLED})^{[5-8]}$ 、有机太阳能电池 ${ }^{[9 \sim 11]}$ 等诸多光电器件, 而 这类材料发展的关键在于新型 $\pi$-共轭分子的研发. 其中 多并环梯形 $\pi$-共轭体系具有许多优点, 如可避免构像无 序性、扩大 $\pi$-共轭、增强体系荧光特性、提高载流子迁

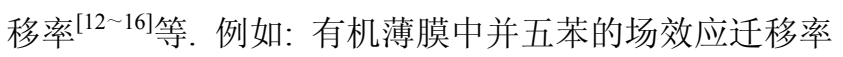
达 $1.5 \mathrm{~cm}^{2} \cdot \mathrm{V}^{-1} \cdot \mathrm{s}^{-1}$, 可以和非晶硅相媲美, 它易形成分 子晶体且在低温基质上能形成有序的薄膜 ${ }^{[17]}$; 在有机 太阳能电池中并五苯可用做 $\mathrm{p}$ - 型材料, 能量转化效率达 $2.7 \%$, 并五苯与 $\mathrm{C}_{60}$ 异质结外量子效率高达 $58 \%$, 成为 太阳能电池和光电探测器领域极具前景的材料 ${ }^{[18]}$.

噻咯(Silole)即硅杂环戊二烯, 其硅原子的环外 $\sigma^{*}$ 轨道与丁二烯的 $\pi^{*}$ 轨道可形成 $\sigma^{*}-\pi^{*}$ 共轭, 有效降低了
体系的 LUMO (Lowest Unoccupied Molecular Orbital, 最低末占轨道)能级, 提高了电子亲合势, 从而利于电 子注入和传输 ${ }^{[19 ~ 22]}$, 因此噻咯及其衍生物具有独特的 电子结构和光、电性质. 如 2,5-双 [6'-(2',2"二二吡啶)]-1,1二甲基-3,4-二苯基噻咯(PyPySPyPy)的电子迁移率高, 比 OLED 中广泛应用的电子传输材料一三(8-羟基喹 啉 $)$ 铝 $\left(\mathrm{Alq}_{3}\right)$ 提高了近两个数量级 ${ }^{[23]}$. 同时噻咯还具有较 高的固态发光量子效率, 如基于噻咯的有机发光二极管 的外量子效率可达 $8 \%{ }^{[24]}$. 硅原子对 $\pi$-共轭体系的电子 结构影响较大, 如噻咯的 LUMO 能级明显低于吡咯、呋 喃、噻吩、吡啶, 用噻咯作为构建单元能够得到具有独 特电子结构的新型 $\sigma$-共轭和 $\pi$-共轭分子 ${ }^{[20]}$.

将多并环梯形 $\pi$-共轭体系与硅杂环戊二烯结构相 结合, 就形成了硅桥联并环梯形共轭体系. 李良春等 ${ }^{[25]}$

\footnotetext{
* E-mail: ququhongmei@126.com

Received December 6, 2013; revised January 19, 2014; published online February 21, 2014.

Project supported by the National Natural Science Foundation of China (No. 21102099).

国家自然科学基金(No. 21102099)资助项目.
} 
按照分子骨架的不同, 分别综述了硅桥联并环共轭体系 光电功能材料的研究进展, 包括有机小分子与聚合物, 所涉及分子的母环中包含苯环、噻咯、噻吩、环戊二烯、 硒杂环戊二烯等结构.

其中, 将硅引入并苯后形成 $\sigma^{*}-\pi^{*}$ 共轭结构可降低 分子的 LUMO 能级, 提高电子亲合势; 同时利用并苯的 刚性共平面结构特性, 可消除构象无序性、增强固相分 子间的 $\pi-\pi$ 电子相互作用、有效扩大 $\pi$-共轭、增强电子 离域、降低分子势垒、利于载流子迁移. 因此含有噻咯 与并苯的分子可能兼具有这两类结构的优点一一发光 效率、载流子迁移率高等, 而在有机光电子领域引起人 们的广泛关注. 一些学者对含有这两类结构的物质进行 了综述报道: 例如 $\mathrm{Fu}$ 等 ${ }^{[26]}$ 报道了可用于发光二极管和 有机光伏器件基于噻咯材料的研究进展, 主要涉及取代 噻咯、二苯并噻咯(Silafluorene)和二噻吩并噻咯衍生物 的光电性能. Corey 等 ${ }^{[27]}$ 对苯并噻咯(Benzosilole)和二苯 并噻咯类物质的合成、表征及应用方面的研究工作进行 了综述.

仅含硅杂环戊二烯和并苯两类结构的有机小分子 化合物, 有关其合成新方法的研究、结构修饰、性能及 其在光电材料等方面的应用研究也在不断深入进行中. 目前有关这类物质的合成、性能等方面专门的综述很少， 因此, 为了更加及时、全面、深入地了解硅杂环戊二烯 并苯有机小分子的最新研究现状, 本文对最近几年关于 其合成、性能等方面的研究进行综述. 本文所讨论的母 环结构仅限于含有苯环和噻咯环, 不包含其他杂环. 主 要按照该类物质结构由简单到复杂的顺序, 依次从噻 咯、苯并噻咯、硅桥联对二苯乙烯衍生物(Silicon-bridged stilbene derivatives)、二茶并噻咯和双硅桥联对三联苯 (Bis-silicon-bridged $p$-terphenyls)等几方面展开综述. 首 先是最简单、最基本的结构一噻咯.

\section{1 噻咯}

噻咯的结构骨架如 1 所示. 噻咯是含硅的五元环, 是环戊二烯的一个碳原子被硅原子取代后得到的, 其硅 原子的环外 $\sigma^{*}$ 轨道与丁二烯的 $\pi^{*}$ 轨道可形成 $\sigma^{*}-\pi^{*}$ 共 轭. 通过对含杂原子的环戊二烯分子进行量子化学的理 论研究 ${ }^{[19]}$ 发现: 噻咯的 LUMO 能级远远低于吡咯、噻 吩、呋喃等五元环, 使得其具有较强的接受电子能力, 在光电材料等领域有广泛的应用. 这类物质首先是由 Braye 和 Hübel ${ }^{[28]}$ 合成报道的, 噻咯类化合物具有独特 的光、电特性, 研究者对有关其合成方法、结构修饰、

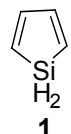

性能和应用进行了广泛研究.

到目前为止, 关于噻咯类物质的综述报道较多, 其 中很多是关于含有噻咯结构的聚合物的报道 ${ }^{[29-38]}$, 这 些综述涉及到含噻咯聚合物的合成、性能及应用方面的 研究工作, 例如 Kularatne 等 ${ }^{[30]}$ 主要对过去十年可用于 有机太阳能电池的供体一受体聚合物的研究进展进行了 评述，其中包括 9,9-二烷基-2,7-荡供体-受体聚合物、 2,7-咔唑供体-受体聚合物、二噻吩并噻咯供体-受体聚 合物等的性能和应用. 唐本忠等 ${ }^{[32]}$ 综述了具有聚集诱 导发光(Aggregation-Induced Emission, AIE)或聚集增强 发光(AEE)性能的发光聚合物的研究进展. 曹镛等 ${ }^{[33]}$ 对 含噻咯聚合物性能和应用方面的研究工作进行了报道. Howell 等 ${ }^{[36]}$ 综述了一种合成方法, 该方法可用于合成 阻燃聚合物卤代芳基取代噻咯. 曹镛等 ${ }^{[37]}$ 评述了可用 于太阳能电池能量转化率高于 $1 \%$ 的供体聚合物的研究 进展. Sanchez 等 ${ }^{[38]}$ 报道了一种合成途径一二 二炔的氢 化硅烷化，该方法可用于合成发光聚合物。除此之外， 一些研究者如 Corey ${ }^{\left[{ }^{[39]}\right.}$ 报道了噻咯类物质的合成、表征 及应用方面的研究工作, 包括含噻咯结构小分子和聚合 物. Ohshita ${ }^{[40]}$ 主要是对含二噻吩并噻咯结构单元低聚物 和聚合物的合成、性能及应用方面研究工作进行了综述 报道. 唐本忠等 ${ }^{[41]}$ 综述了基于 AIE 噻咯小分子和聚合物 的合成、性能及应用方面的研究工作. Moustafa 等 ${ }^{[42]}$ 评 述了含噻咯结构半导体材料的合成、性能及光电应用方 面的研究工作, 包括噻咯类小分子和聚合物. 而有一些 报道 ${ }^{[44 ~ 50]}$ 是只关于噻咯类小分子物质的合成、性能及应 用方面的研究工作. Ohmura ${ }^{[44]}$ 主要报道了一种过渡金 属催化下将硼基和硅烷基引入到不饱和有机小分子化 合物中的方法，该方法也可用于合成噻咯衍生物. 唐本 忠等 ${ }^{[45}$ 综述了具有凝胶诱导发光性能的有机发光凝胶 有关研究工作, 其中涉及到含有噻咯结构的有机凝胶物 质. Tobisu 等 ${ }^{[46]}$ 报道了一种通过活化内在化学键而进行 的取代反应，其中包括活化三甲基硅烷基的 $\mathrm{C}-\mathrm{Si}$ 键来 合成噻咯类物质的方法. 但含有噻咯结构的小分子物质 的研究工作仅是这几篇综述的一小部分. 此外, 虽然马 庆宇 ${ }^{[47]}$ 、张运生 ${ }^{[48]}$ 、唐本忠 ${ }^{[99]}$ 和毛林燕等 ${ }^{[50]}$ 综述的主 要对象是噻咯类物质, 但涉及的研究工作较早, 有一定 的局限性.

本节主要集中于母环结构仅为噻咯环的小分子化 合物的研究. 首先是关于其合成方法及结构修饰方面的

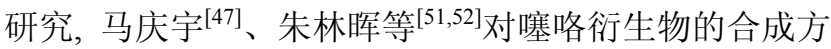
法以及结构修饰进行了概述. 在此基础上, 我们对近几 年关于噻咯衍生物合成的研究报道评述如下:

反应过程如 Scheme 1 所示: 以二甲基二苯乙炔基 硅烷为原料, 依次在 $\mathrm{LiNaph}, \mathrm{ZnCl}_{2}, \mathrm{NCP}$ 和 $\mathrm{I}_{2}$ 作用下, 


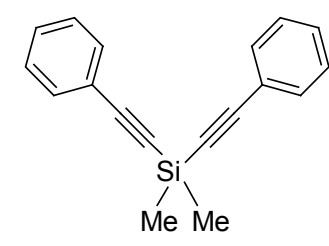

(1) LiNaph (2) $\mathrm{ZnCl}_{2}$

(3) NCP

(4) $\mathrm{I}_{2}$
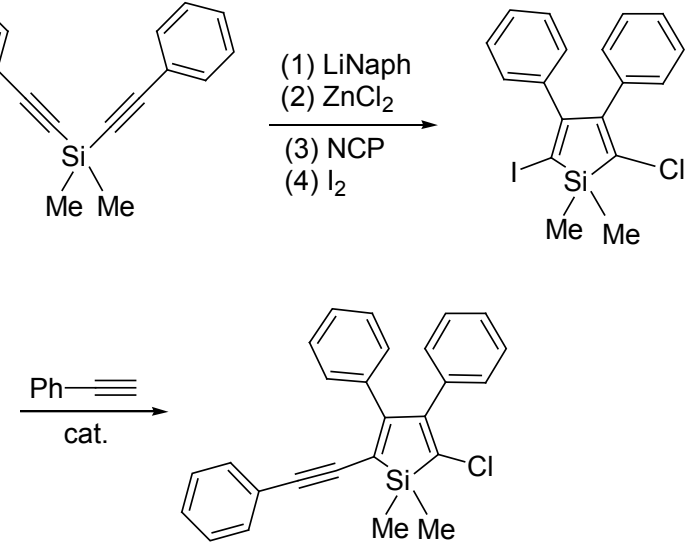

Scheme 1

发生分子内还原关环反应, 合成得到 2,5 位具有不同卤 素取代的噻咯衍生物-2-氯-5-碘-1,1-二甲基-3,4-二 苯基硅杂环戊二烯. 该衍生物是制备 2,5 位具有不同官 能团取代的硅杂环戊二烯的关键物质. 该物质再与苯乙 炔在催化剂作用下, 通过偶联反应制得 2,5 位分别为苯 乙炔基和氯原子取代的 1,1-二甲基-3,4-二苯基硅杂环戊 二烯 ${ }^{[53]}$. 该过程反应温度较低, 条件苛刻, 要求无水无 氧; 中间产物 2-氯-5-碘-1,1-二甲基-3,4-二苯基硅杂环戊 二烯不稳定, 需要避光; 且反应对催化剂的活性也有一 定要求; 这在一定程度上限制了其应用.

通常向 1,1 位引入甲基或苯基, 若想获得其它新型 噻咯衍生物, 则需要通过在 2,3,4,5 位进行修饰, 而 2,5 位引入不同的官能团比较容易, 相关的研究报道也较 多. 预期 2,5 位具有噻吩基取代的噻咯衍生物具有良好 的性能. 汪峰等 ${ }^{[54]}$ 同样以二甲基二苯乙炔基硅烷为原 料, 在 LiNaph 和 $\mathrm{ZnCl}_{2}$ 作用下进行还原关环反应, 进而 再与 2-溴噻吩在催化剂作用下反应生成 1,1-二甲基-3,4二苯基-2,5-双 (2'-噻吩基)噻咯(TST, 2)所示, 收率为 $56 \%$. 该合成过程要求无水无氧, 条件苛刻, 且收率较 低.

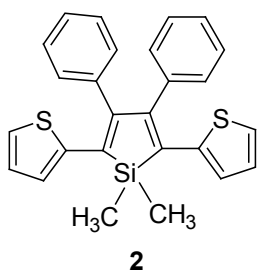

除此之外, 还有学者以二苯乙炔为原料, 在有机锂 的作用下, 得到 1,4-二锂-1,2,3,4-四苯基丁二烯, 再与不 同取代的二氯硅烷发生关环反应生成 1,1 位不同取代的 2,3,4,5-四苯基噻咯. 该反应要求无水无氧, 条件苛刻, 成本较高 ${ }^{[55,56]}$.

合成方法研究是噻咯研究的一个重要组成部分. 合 成的主要目的之一是为了研究其性能, 进而将其进行应
用. 因此，除了有关噻咯合成及修饰的报道外，不少学 者还对噻咯类物质的性能进行了实验研究, 发现了各种 有趣的实验现象. 例如 AIE 现象 ${ }^{[24]}$, 首次由唐本忠课题 组发现, 噻咯衍生物在溶液状态下不发光, 但在固体状 态或纳米颗粒状态时却发出很强的光. 这一现象与一般 有机材料的发光行为恰恰相反, 因此, 噻咯类物质这一 罕见的性能引起了大家广泛的关注.

基于 AIE 现象, 唐本忠课题组 ${ }^{[57]}$ 又进一步研究了噻 咯衍生物的性能和在光电器件方面的应用. 1,1 位取代 的 2,3,4,5-四苯基噻咯在正常的室内光照条件下可观察 到强烈的蓝光，而 1,2,3,4-四苯基丁二烯却无此现象，这 是因为硅杂环戊二烯的刚性共平面结构在产生固态光 致荧光现象中起到了重要作用. 噻咯 1,1 位取代基可调 节化合物的电子结构和性能, 苯环的诱导共轭效应使得 被苯环取代的噻咯具有低的 LUMO 能级和高的发射效 率. 1,1 位取代基的电负性对化合物的 $\lambda_{\mathrm{ab}}, \lambda_{\mathrm{em}}$ 和能隙 $E_{\mathrm{g}}$ 影响较大, 对 $\varphi_{\mathrm{F}}$ 几乎没有影响 ${ }^{[58]}$. 基于 1 -甲基-1,2,3, 4,5-五苯基噻咯的电致荧光器件在 $18 \mathrm{~V}$ 电压下亮度达 $4538 \mathrm{~cd} / \mathrm{m}^{2}$, 在 $17 \mathrm{~V}$ 电压, 电流密度为 $94 \mathrm{~mA} / \mathrm{cm}^{2}$ 下外 量子效率达 $0.65 \%$, 这表明噻咯类化合物有望作为良好 的苂光材料应用于有机发光二极管器件 ${ }^{[57]}$ 中. 基于噻 咯的有机发光二极管具有良好的性能, 苂光电流效率为 $20 \mathrm{~cd} / \mathrm{A}$ ，相当于外量子效率为 $8 \%{ }^{[59]}$.

关于噻咯类物质的性能研究, 毛林燕等 ${ }^{[50]}$ 进行了 综述报道, 随后有一些研究者也作了相关的研究. 汪峰 等 ${ }^{[54]}$ 对合成得到的噻咯衍生物 TST 进行性能实验, 研 究了其在不同比例 THF 和水混合液中的紫外可见吸收 光谱, 结果发现: 在 THF 中化合物 TST 在 $413 \mathrm{~nm}$ 处有 吸收峰. 当混合溶液中水体积比增加到 50\%时, 吸收峰 出现红移. 这是由于 1,1-二甲基-3,4-二苯基-2,5-双(2'-噻 吩)噻咯(TST)发生聚集, 分子间作用所致. 荧光光谱研 究发现该化合物具有良好的聚集诱导发光增强效应以 及低温苂光增强效应，抑制塞咯分子内 2,3,4,5 位官能团 的自由旋转可使荧光增强. TST 由于具有固态强发光的 优点, 可作为发光材料应用于有机电致发光器件中.

随着对噻咯类物质研究工作的不断深入, 有关应用 方面的进展也不断见诸于报道. 目前噻咯衍生物在光电 材料、生物传感器及化学传感器等方面的应用已有不 少研究者进行综述报道, 这方面的研究进展可参见马庆 宇 ${ }^{[47]}$ 、张运生 ${ }^{[48]}$ 和唐本忠等 ${ }^{[49]}$ 的文章.

综上所述，我们发现合成噻咯类物质的原料局限于 乙炔和二炔类, 噻咯的合成方法有限, 且操作条件苛刻, 因此探索新的、收率更高且普遍适用的官能化噻咯的 合成方法依然是今后研究工作的重点. 对于其结构的修 饰主要集中在 1,1 位、2,5 位和 3,4 位，一般都是苯基或 
烃基取代，尝试向 3,4 位引入其它取代基进行修饰的工 作仍有待于进一步的探索, 以获得更多新的衍生物. 噻 咯类衍生物良好的性能主要集中在光电材料方面, 其器 件研究有一定局限性; 它们多用于发光二极管, 用于太 阳能电池、场效应晶体管等方面的研究则相对较少. 因 此我们应该进一步深化其在太阳能电池、场效应晶体 管等方面的应用研究，拓展其在生物检测、化学检测等 领域的应用.

\section{2 苯并噻咯}

苯并噻咯即硅狮(Silaindene), 结构如 3 所示. 这类 物质首次是由 Barton 等 ${ }^{[60]}$ 合成得到的.

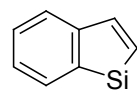

苯并噻咯合成方法主要包括：热诱导乙炔-亚乙烯 基重排反应、分子内还原环化反应、铁催化加成环化 反应、金复合物催化的分子内烯丙基转移硅烷化反应 和一锅法反应即镍催化氢化硅烷化后铱催化的脱氢环 化反应. 分别讨论如下:

以邻-二甲基硅烷基苯乙炔(4)为原料, 通过热诱导 分子内乙炔-亚乙烯基重排得到 1, 1 - 二甲基 - 1 硅狮(6). 该反应过程为: 在 $800{ }^{\circ} \mathrm{C}$ 下, 化合物 4 热解产 生化合物 $\mathbf{5}$, 化合物 $\mathbf{5}$ 的亚乙烯基插入到 $\mathrm{Si}-\mathrm{H}$ 键处得 到 6, 收率达 $84 \%$, 如 Scheme 2 所示. 但反应温度对收 率影响较大: 当温度为 $700{ }^{\circ} \mathrm{C}$ 时, 收率降至 $77 \%$, 且有 6 的异构体产生; 当温度为 $650{ }^{\circ} \mathrm{C}$ 时, 分子 6 的收率更 低, 仅为 47\%. 研究结果表明热诱导乙炔-亚乙烯基重 排为合成不饱和含硅环状化合物提供了一条途径, 但该 反应所需原料需要经过多步反应才能合成得到, 而且反 应温度较高 ${ }^{[60]}$.

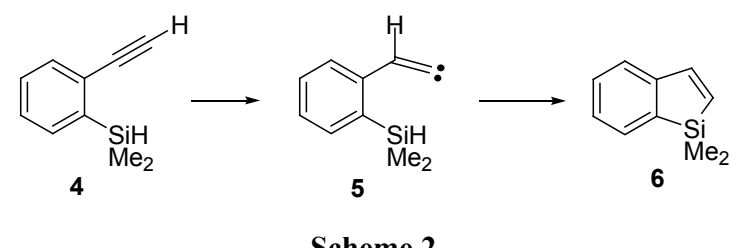

Scheme 2

Yamaguchi 等 ${ }^{[61]}$ 以苯基-邻-(二甲基硅烷基)苯基乙 炔(7)为原料, 在 2 equiv. LiNaph 作用下, 发生分子内乙 炔部分的双电子还原，产生双阴离子中间体，然后再经 过环化反应得到 1,1-二甲基-2-苯基硅狮 $(8)$, 收率仅 17\%，还生成 74\%二聚体，具体如 Scheme 3 所示. 该反 应条件简单，操作简便，时间短，室温下 $5 \mathrm{~min}$ 内即可完 成, 反应原料可选用各种邻一硅烷基苯基乙炔类衍生物.
基于此方法，他们又以含有邻-(硅烷基)苯基乙炔结构 的各种 $\pi$-共轭化合物为原料反应合成了一系列含硅狮 结构的 $\pi$ 电子体系，如 9 11 所示. 由此可见，此方法可 作为合成各种官能化含硅狮结构 $\pi$ 电子体系的一条反应 途径。这些化合物均呈现出强烈蓝-蓝绿色苂光，有可 能作为发光材料.

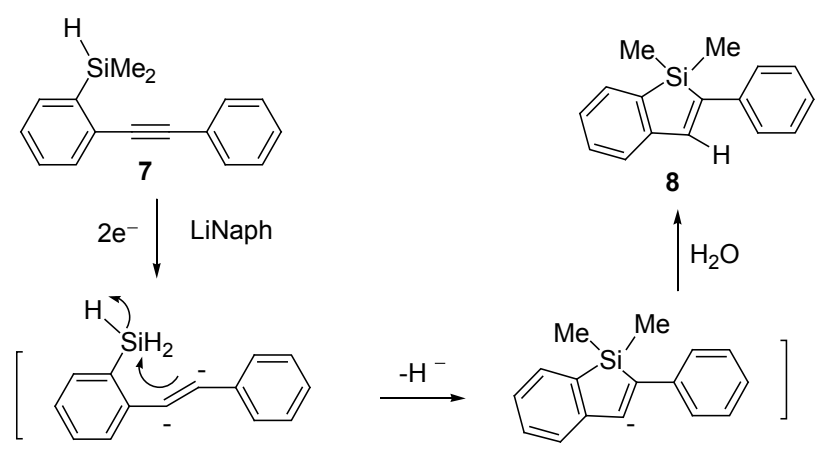

Scheme 3

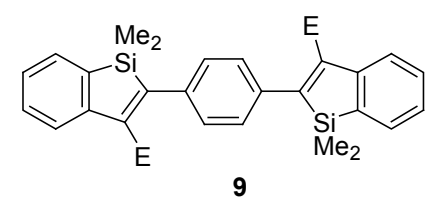

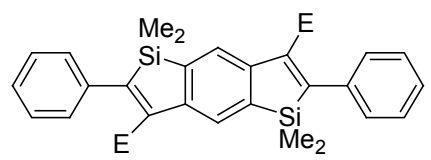

10

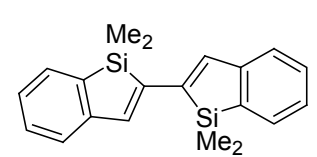

11
邻位烷基取代苯基锂或顺式烷基取代乙烯基锂在 $5 \% \mathrm{Fe}(\mathrm{acac})_{3}$ 作用下很容易与炔烃发生加成反应. 在此 基础上, Shirakawa 等 ${ }^{[62]}$ 运用 1 equiv.不同烷基取代炔烃 12 与 1.6 equiv. 邻-(三甲基硅烷基)苯基锂(13), 在 5\% $\mathrm{Fe}(\mathrm{acac})_{3}$ 催化作用下, 依次经过加成、环化反应得到一 系列苯并塞咯衍生物, 14 过程如 Scheme 4 所示. 在低温 下 13 与芳基炔反应得到相应取代苯并噻咯衍生物，该 反应具有高度区域选择性，反应温度较低且产率较高. 但该反应对原料苯基锂或烯基锂的结构有一定要求，需 要苯基锂的邻位或烯基锂的顺式有烷基取代.

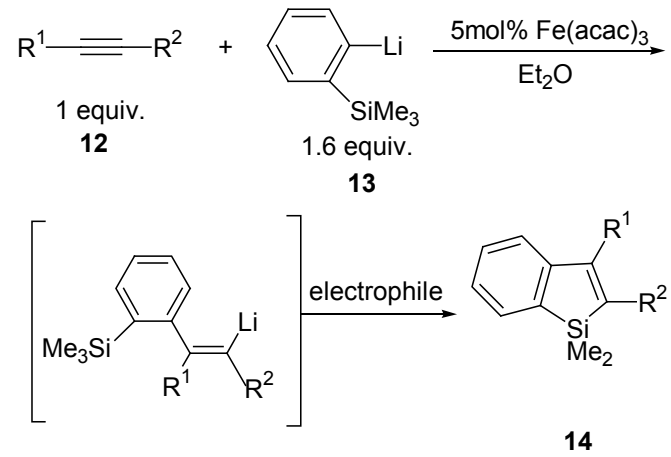

Scheme 4 
Yamaguchi 等 ${ }^{[63]}$ 以 15 为原料, 在金复合物催化作 用下，通过分子内烯丙基转移硅烷化反应，合成了 2 位 具有不同取代的 3-烯丙基-1-硅狮(16), 过程如 Eq. 1 所 示. 金复合物配体对反应收率影响较大, 当原料分子中 $\mathrm{R}$ 为丙基、催化剂配体为 2-双叔丁基膦基二联苯时, 反 应收率高达 $97 \%$. 该反应操作简单, 反应温度较低, 适 用性强，但反应对原料结构中炔基上的取代基 $\mathrm{R}$ 有一定 要求, 端炔或有较大取代基的炔烃不能进行此反应. 通 过对原料中烯丙基硅烷基部分的结构调整, 可得到 $\gamma$ 位 烯丙基化产物, 而且该反应具有区域选择性. 他们不仅 对硅䒢衍生物的合成方法和结构修饰进行了研究, 而且 还对合成得到的硅狮衍生物进行了荧光光谱和量子效 率研究, 发现硅䒢衍生物在 $250 \mathrm{~nm}$ 紫外照射下具有荧 光现象, 其中 $\mathrm{R}$ 为丙基的产物在 $361 \mathrm{~nm}$ 处呈现苂光, 量 子效率为 0.07 .

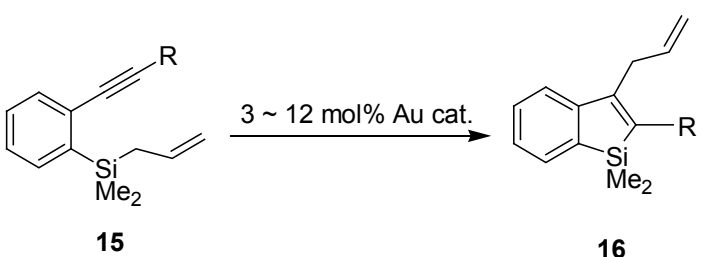

基于此方法, 以(邻-乙炔基)苯基-异丁烯基-二甲 基硅烷作为反应物, 在室温条件下, 由金复合物催化反 应得到 17. 氛标示法研究得知此反应机理是烯丙基转 移硅烷基化而不是烯炔的移位, 这与实验结果相一 致 ${ }^{[64]}$. 上述合成方法中, 分子内还原环化反应操作简 便, 反应时间短; 铁催化加成环化反应区域选择性较高, 且收率较高. 有些采用含有苯乙炔结构化合物作为原 料, 但是与来源广泛, 价格更便宜的苯乙烯相比, 苯乙 炔类物质不具有优势. 因此有些研究者尝试以苯乙烯衍 生物为原料来合成苯并噻咯类物质.

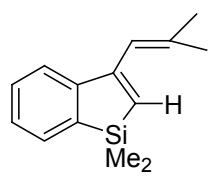

17

如 Kuznetsov 等 ${ }^{[65]}$ 以不同取代苯乙烯为原料, 在催 化剂作用下, 通过一锅法合成二氢化苯并噻咯衍生物, 如 Scheme 5 所示. 该方法首先采用镍催化苯乙烯衍生 物发生氢化硅烷化反应, 所得中间产物再于铱催化作用 下发生脱氢环化反应, 生成二氢化苯并噻咯衍生物.

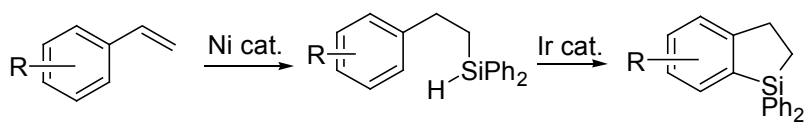

Scheme 5
经研究发现, 以便宜易得的 $\mathrm{NiCl}_{2}\left(\mathrm{PPh}_{3}\right)_{2}$ 和 $\mathrm{NiBr}_{2}\left(\mathrm{PPh}_{3}\right)_{2}$ 作为催化剂进行苯乙烯氢化硅烷化时, 反 应收率较高, 且具有较高区域选择性. 在第一步反应基 础上，再经过铱催化脱氢环化反应可以得到 1,1-二苯基2,3-二氢化硅狮(18)所示. 该一锅法反应方法简单，操作 简便, 反应条件温和, 收率较高, 区域选择性较好, 实 用性强，该反应为合成不同官能化二氢化苯并噻咯衍生 物提供了一条有效途径. 但该反应用到两种催化剂, 成 本较高, 反应后期处理麻烦.

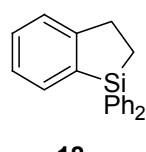

18

如 Scheme 6 所示, 二氢化苯并噻咯衍生物在 DDQ 作用下能够生成相应苯并噻咯衍生物.

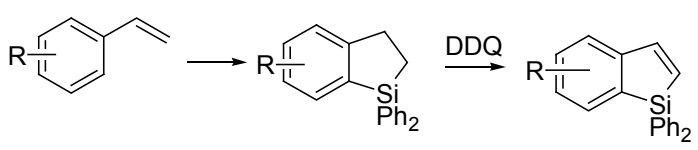

Scheme 6

苯并噻咯类物质的研究报道多集中在合成方法和 结构修饰等方面. 就反应类型来说, 这类物质的合成方 法可分为五类, 各有优缺点和各自适用范围. 而按照原 料类型则可分为苯乙炔和苯乙烯类, 以来源广泛的苯乙 烯类衍生物作为原料的研究报道相对还比较少. 目前关 于苯并噻咯类物质的研究还很有限, 我们应当加强对这 类化合物的研究, 选择更加价廉易得的苯乙烯类物质作 为反应原料, 寻找成本更低、操作更简便的合成途径. 而目前鲜见有关它们性能和应用方面的研究报道, 因此 加强性能研究, 合成具备良好光电性能的材料, 应用于 光电器件等领域将是我们今后工作的重点.

\section{3 硅桥联对二苯乙烯衍生物}

硅桥联对二苯乙烯衍生物的骨架结构为 5,10-二硅 狮并[2,1- $a$ ]狮(19)所示, 是由 Barton 等 ${ }^{[66]}$ 于 1997 年首次 报道的，他们合成得到的 5,5,10,10-四甲基-5,10-二硅狮 并 $[2,1-a]$ 狮 $(\mathbf{2 0})$, 具有强烈蓝色荧光, 因此有望作为蓝 色发光材料.

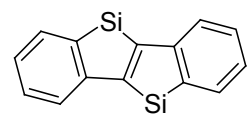

19

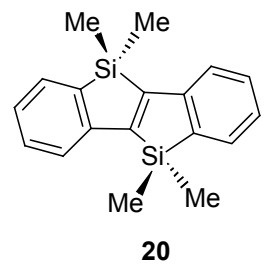

20
一些学者对硅桥联对二苯乙烯衍生物进行了研究 
报道. 其中 Yamaguchi 小组 ${ }^{[67]}$ 在此方面做了许多工作. 如 Eq. 2 所示, 以双(邻-二甲基硅烷基)-二苯基乙炔为起 始原料, 在 4 equiv. 还原剂 LiNaph 作用下, 乙炔部分发 生分子内双电子还原, 产生一个双阴离子中间体, 然后 再经过双环化反应, 最终用碘来淬灭, 得到如分子 20 所 示产物，收率 $71 \%$. 该方法操作简便，反应时间较短， 在室温下 $5 \mathrm{~min}$ 内即可完成, 收率高, 实用性强, 可用于 合成硅桥联对二苯乙烯衍生物.

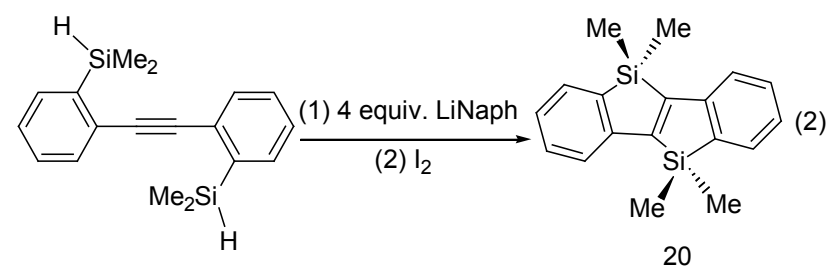

Scheme 7

基于此方法, 他们 ${ }^{[67]}$ 又以 $\mathbf{2 1}$ 为起始原料, 在 8 equiv. 还原剂 LiNaph 作用下, 室温反应得到第一个四硅 桥联衍生物 22, 反应过程如 Scheme 7 所示. 该产物为亮 黄色固体, 收率高达 91\%. 但该反应需要耗费大量还原 剂和碘，这在一定程度上限制了其应用.
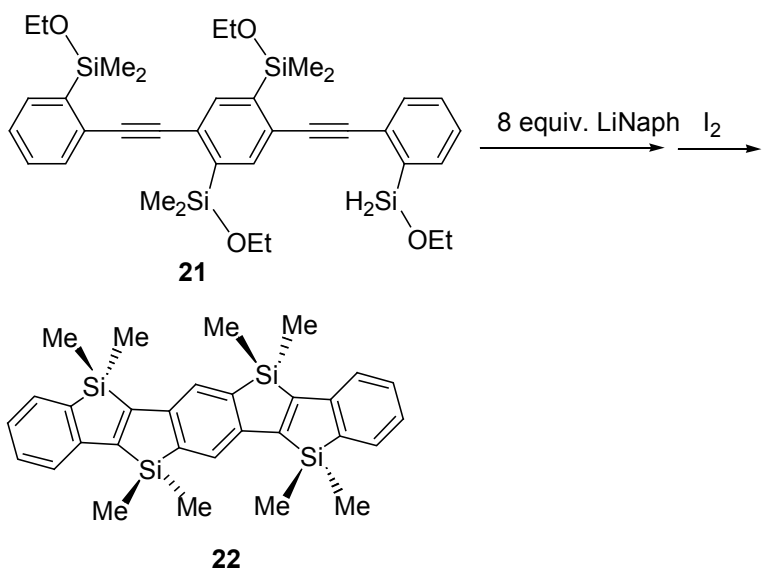

\section{Scheme 7}

他们不仅研究了硅桥联对二苯乙烯衍生物的合成 方法, 而且还成功运用此方法得到了一系列新型硅桥联 对二苯乙烯衍生物. 此外, 还对所得衍生物进行了 $\mathrm{X}$ 射 线晶体学分析, 研究了吸收、苂光光谱以及量子效率等 光物理性能, 探讨了分子结构与性能之间的内在关系. 其中, 22 具有高度共平面结构, 且中心苯环和外侧苯环 的二面角仅为 $3.9^{\circ}$, 整个分子为 $\pi$ 共轭体系. 由于硅原 子的引入，与相应碳类似物 $\mathbf{2 3}$ 相比, 20 的吸收峰和发射 峰均向长波方向分别移动 40 和 $60 \mathrm{~nm} .20$ 激发态辐射衰 变过程较慢, 它的苂光量子效率为 0.58 , 比分子 23 略 低. 与四个环的 20 相比, 7 个环的分子 22 由于 $\pi$ 共轭的 扩大，吸收峰和发射峰均分别向长波方向移动了 64 和
$47 \mathrm{~nm}$, 然而荧光量子效率却几乎没有发生变化, 为 0.50. 研究可以观察到 22 能够发出强烈的蓝绿色苂光, 因此该分子是一种具有潜在应用价值的发光材料。

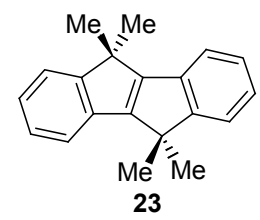

除此之外, 徐彩虹等 ${ }^{[68]}$ 也对硅桥联对二苯乙烯衍 生物的合成方法进行了研究，如 Scheme 8 所示，他们将 双(邻一硅烷基苯基)乙炔的合成和其自身的分子内还原 环化反应结合在一起，获得了一条新型合成路线一一 锅法反应. 采用此法, 以双(邻一溴苯)乙炔衍生物 24 为 原料，合成了硅桥联对二苯乙烯衍生物 25 . 以双(邻-溴 苯)乙炔衍生物为原料, 该一锅法反应的收率与两步法 反应总收率相当，这说明分子内还原双环化反应对反应 条件要求不高，第一步反应产生的一些杂质对硅桥联对 二苯乙烯衍生物的收率几乎没有影响.

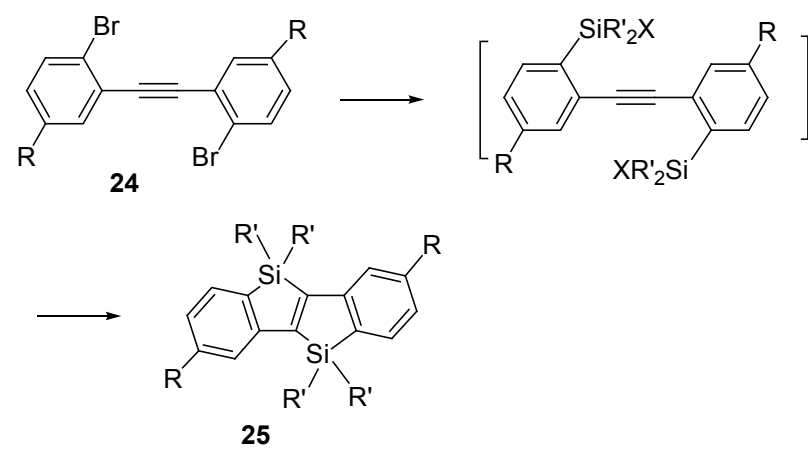

\section{Scheme 8}

除了硅桥联对二苯乙烯衍生物合成方法的研究之 外, 还有一些学者对它们的性能进行了研究报道. 例如 Kan 等 ${ }^{[69]}$ 进行了量子化学研究, 探讨了电子结构对分子 吸收、发射性能的影响。他们采用杂化密度泛函 (B3LYP)在基组 6-31G $(\mathrm{d})$ 水平上对 20 和相应碳类似物 23 的基态几何结构进行优化，描述了它们的前线分子 轨道. 研究发现 20 的 LUMO 能级比 23 低 $0.46 \mathrm{eV}$, HOMO 能级仅比 23 的略低 $0.14 \mathrm{eV}$, 这样 $\mathbf{2 0}$ 具有更小 的 HOMO-LUMO 能陌. 这是由于硅原子的引入，扩大 了 $\pi$ 共轭, 有效降低了分子 LUMO 能级, 而对 HOMO 能级几乎没有影响，从而缩小了分子的 HOMO-LUMO 能隙. 电离能(IP)和电子亲合能(EA)计算结果表明：硅 桥联对二苯乙烯衍生物比相应碳类似物具有更强的捕 获电子能力. 由此可见，硅桥联对二苯乙烯衍生物有作 为电子传输材料应用的潜质. 他们又运用 Hartkee-Fock 单组态相互作用方法(CIS)、含时密度泛函理论(TD- 
DFT)和 Zemer 间略微分重叠方法(ZINDO)研究了有关 物质的吸收和苂光光谱, 结果发现, 与相应碳类似物 23 相比, 硅桥联对二苯乙烯衍生物 20 的吸收和发射峰均 向长波方向分别移动了 45 和 $85 \mathrm{~nm}$, 发光颜色位于蓝色 区域. 预期可通过引入硅原子, 从而获得具有较长波段 的化合物; 四硅桥联对二苯乙烯衍生物 22 强烈的蓝绿 色荧光 ${ }^{[67]}$ 恰好证实了这一构想. 上述有关硅桥联对二 苯乙烯衍生物性能的理论研究, 为我们获得新型电子传 输材料及发光材料提供了一定的思路和指导.

综上所述, 关于硅桥联对二苯乙烯衍生物的研究报 道还很少. 有关合成方法也比较有限, 主要是双(邻-硅 烷基苯基)乙炔类物质的还原环化反应，尽管该方法操 作简便, 反应时间较短, 但需要耗用大量的还原剂 LiNaph 和碘. 因此, 我们应该继续致力于研究成本更 低, 收率更高的反应条件, 同时开发新的合成方法. 不 仅限于乙炔类物质, 还应尝试其它诸如乙烯类物质等原 料, 获得更多新型硅桥联对二苯乙烯衍生物. 值得注意 的是目前有关这类物质性能的研究少之又少, 更是鲜见 将其应用于器件等方面的研究报道, 因此更加值得深入 研究.

\section{4 二苯并噻咯}

二苯并噻咯即硅杂芴或硅芴, 结构如 26 所示. 它是 最简单的硅桥联并苯联苯共轭体系, 是二苯并环戊二烯 (简称芴)的类似物. 芴衍生物由于具有良好的电子和光 学性能、较高的热、化学稳定性以及容易制得等优点, 目 前已经得到了广泛地研究 ${ }^{[70 ~ 72]}$. 硅芴相当于芴的 9 位碳 原子被硅原子取代所得，噻咯环位于分子的中间位置， 引入硅原子后环外 $\sigma^{*}$ 轨道与丁二烯的 $\pi^{*}$ 轨道可形成 $\sigma^{*}-\pi^{*}$ 共轭, 可有效降低体系 LUMO 能级, 利于电子注 入传输, 从而赋予此类物质较高的电子和光学性能, 有 可能作为电子传输材料、发光材料等, 在 OLED、太阳 能电池等方面具有一定应用前景. 它们最早是由 Gilman 等 ${ }^{[73]}$ 于 1955 年报道. 自此之后, 围绕其合成、 结构修饰和性能等方面的研究不断见诸于报道.

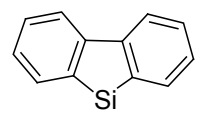

26

目前关于二苯并噻咯类物质的报道主要集中在基 于硅䓄的聚合物研究等方面, 如曹镛等 ${ }^{[74]}$ 综述了含噻 咯聚合物的合成和光电性质, 其中包括基于二苯并噻咯 的聚合物; Beaupré 等 ${ }^{[75]}$ 对用于太阳能电池和发白光二 极管的基于桥联亚苯基共轭聚合物的合成和表征进行 了综述报道，其中包括基于 2,7-二苯并噻咯的聚合物.
但是，最近几年也出现了一些关于二苯并噻咯类小分子 物质的综述报道, 如 Fui 等 ${ }^{[26]}$ 的综述主要是关于硅苆类 物质的光电性能; Corey ${ }^{[27]}$ 的综述包括二苯并噻咯类小 分子物质. 但是这些综述报道都各有侧重, 有一定的局 限性，因此，本节拟对二苯并噻咯类小分子物质的相关 研究进行综述, 主要包括它们的合成方法、结构修饰以 及相关性能研究.

化合物的性能是由其结构决定的，而结构则是通过 不同方法合成和修饰得到的，因此研究化合物的合成方 法以及结构修饰对进一步研究其性能和应用具有重要 意义. 到目前为止, 二苯并噻咯小分子的合成方法还比 较有限，主要包括卤素-金属交换后再环化的反应、过渡 金属催化反应、分子内硅-Friedel-Crafts 反应和金属铑催 化 $\mathrm{Si}-\mathrm{H}$ 键和 $\mathrm{C}-\mathrm{H}$ 键双活化脱氢反应. 分别讨论如下:

如 Scheme 9 所示, Gilman 等 ${ }^{[73]}$ 以 2,2'-二澳联苯为原 料, 在 2 equiv.正丁基锂作用下, 卤素与锂发生交换, 得 到 2,2'二锂联苯. 然后再与等量二苯基二氯硅烷环化反 应合成 9,9-二苯基二苯并噻咯(27). 该反应操作条件苛 刻, 分离纯化比较困难且收率较低. 进一步研究发现: 与相应碳类似物相比, 该物质不仅熔点较低, 而且气化 温度更高, 表明该物质具有较好的热稳定性.

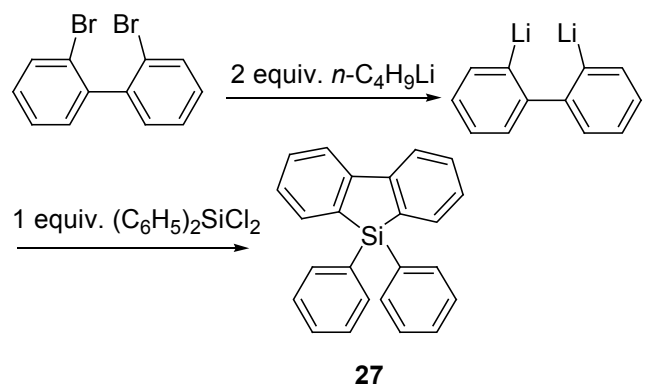

\section{Scheme 9}

随后他们又运用同样方法合成得到 2,2'-二锂联苯， 进而与具有不同取代的二氯硅烷或三氯硅烷环化反应 得到不同官能化二苯并噻咯衍生物 ${ }^{[76]}$. 当与不同取代 二氯硅烷反应时, 产物收率较低; 但当与三氯硅烷反应 时, 得到官能化二苯并噻咯衍生物 $\mathbf{2 8}$, 收率较高. 当三 氯硅烷取代基为正十二烷或苯基时, 产物纯度很高, 尤 其是当取代基为苯基时，回流状态下将 2,2'-二锂联苯滴 加到苯基三氯硅烷中, 可得纯度很高的产物; 所得产物 进一步与适当有机锂试剂反应可获得不对称取代二苯 并噻咯衍生物. 基于此方法, 同样可以合成得到 9,9-二 苯基硅芴，收率为 70\%. 这证实了对于具有对称取代基 二苯并噻咯衍生物的合成，该两步反应方法比上述一步 反应 ${ }^{[73]}$ 效果更好, 收率更高. 该方法可用于获得硅原子 上具有不同取代基的二苯并噻咯衍生物. 研究还发现运 
用该方法得到的一些具有不对称取代基大分子量二苯 并噻咯衍生物的气化温度较高, 可达 $450{ }^{\circ} \mathrm{C}$, 稳定性较 好, 有可能作为高温下的润滑剂或液压油使用, 但该反 应同样具有操作条件苛刻等不足.

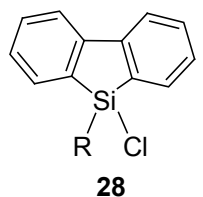

基于此方法, 有学者对化合物的结构进行了修饰, 得到了一些 2,7 位官能化二苯并噻咯衍生物. 例如 Chan 等 ${ }^{[77]}$ 以 1,4-二澳-2-硝基苯为原料, 经过三步反应得到 2,2'-二碘-4,4'-二澳联苯, 再通过卤素-金属交换后再环 化的反应, 最终得到一种二苯并噻咯衍生物 29, 收率 $52 \%$. 29 进一步双锂化再硼化反应后得到另一硅芴衍生 物 30. 这些 2,7-官能化二苯并噻咯衍生物的合成为进一 步合成具有高能隙的发光聚合物提供了一条途径. Huang 等 ${ }^{[78]}$ 以邻联茴香胺为原料, 通过 Sandmeyer 反应 和碘代反应得到 6,6'-二碘-4,4'-二溴-3,3'-二甲氧基联苯, 总收率达 93\%. 进一步经过卤素-金属交换后环化反应 得到了 2,7-二澳-9-杂芴, 当杂原子为 $\mathrm{Si}$ 时, 即为二苯并 噻咯衍生物 31.

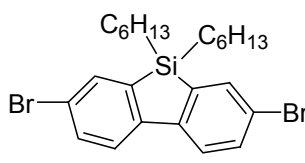

29<smiles>[R][Si]1([R])c2cc(Br)c(OC)cc2-c2cc(Br)c(OC)cc21</smiles>

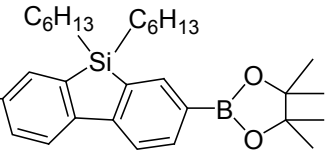

30
卤素-金属交换后再环化的反应尽管应用广泛，但 一般都需要采用有机锂试剂, 操作条件要求比较苛刻. 过渡金属催化合成硅芴衍生物的反应一般不需要锂试 剂，主要是采用金属铱或钯进行催化反应.

Matsuda 等 ${ }^{[79]}$ 研究报道了硅桥联 1,6-二炔与另一烷 基炔在过渡金属铱催化下，通过 $[2+2+2]$ 环加成反应， 合成得到二苯并噻咯衍生物的过程, 如 Eq. 3 所示, 以 简单易制得的二甲基(苯乙炔基)[2-(苯乙炔基)苯基]硅 烷为原料，在铱和三苯基膦的催化作用下，与 2 equiv. 的 1,4-二甲氧基丁-2-炔在丁醚溶剂中 $110{ }^{\circ} \mathrm{C}$ 下反应 24 $\mathrm{h}$ ，最终得到 2,3-双(甲氧基甲基)-1,4-二苯基-9,9-二甲基 二苯并噻咯(32), 收率 86\%。研究发现, 该反应对溶剂 也有一定要求, 尤以丁醚为溶剂时反应收率高. 该 $[2+$ $2+2$ ]环加成反应所必需的核心骨架是 Eq. 3 所示原料: 含苯环的硅桥联 1,6-二炔, 采用含不同取代基的二炔为 原料，可合成多种梯形硅䓄衍生物. 但该反应存在一定
的局限性，对另一原料烷基取代炔烃的结构有一定限 制: 当以含吸电基的 $\mathrm{DMAD}$ (丁炔二酸二甲酯)为原料 时，反应收率仅为 7\%. 此外，该方法只能向噻咯的两侧 并入苯, 而不能并入菜、葸等结构.
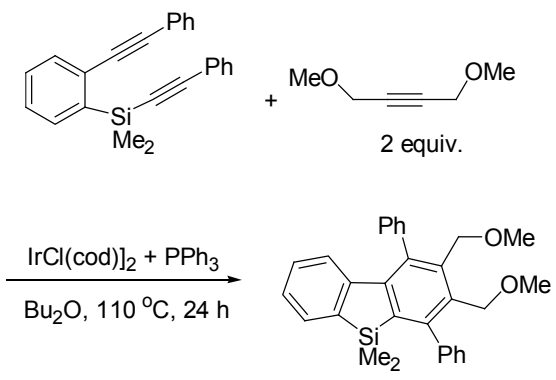

Shimizu 等 ${ }^{[80]}$ 以 2-(苯基硅烷基)苯基三氟甲烷磺酸 酯类物质为原料，碱性条件、 $\mathrm{Pd}$ 催化作用下，经过分子 内偶联反应合成具有二苯并噻咯结构化合物 33, 收率 较高，具体过程如 Eq. 4 所示. 该反应原料仅限于具有 2-(苯基硅烷基)苯基三氟甲烷磺酸酯结构物质, 而且要 求具有较大取代基，这类原料需要经过很多步反应才能 制得. 该反应温度较高, 需要碱性条件, 且只能为有机 碱尤其仲胺时效果较好.
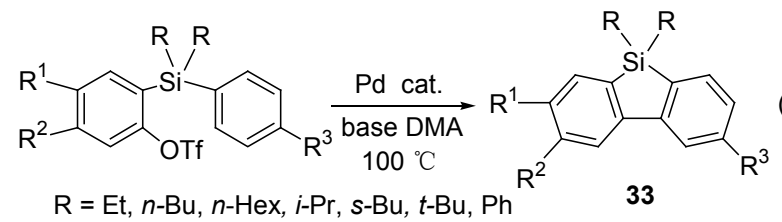

Yabusaki 等 ${ }^{[81]}$ 报道了 $\mathrm{Pd}$ 催化双分子内芳基化反应. 如 Eq. 5 在 $N, N$-二异丙基乙胺存在、双(三叔丁基膦)钯 催化下，与双取代硅烷通过双分子内芳基化环化反应得 到不同取代二苯并噻咯衍生物 34. 该方法室温反应，条 件温和，当原料之一的硅烷上具有较小取代基时反应选 择性较高，但反应时间较长。

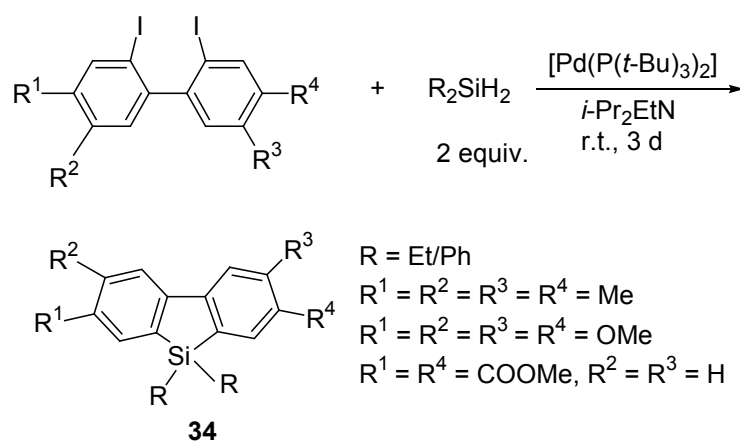

上述过渡金属催化合成反应条件温和，收率高. 但 是原料不易获得，来源受限，一般需经过多步反应才能 制得所需原料.

Furukawa 等 ${ }^{[82,83]}$ 以 2-(二苯基硅烷基)-4,4'-二叔丁基 
联苯为起始原料, 在二氯甲烷、碱性条件和氧化剂作用 下，通过分子内硅-Friedel-Crafts 反应，合成得到硅芴衍 生物 35, 过程如 Eq. 6 所示. 该反应对溶剂、碱和氧化 剂类型有一定要求, 例如溶剂只能为二氯甲烷, 碱仅限 2,6-二甲基吡啶，当氧化剂为 $\mathrm{Ph}_{3} \mathrm{CB}\left(\mathrm{C}_{6} \mathrm{~F}_{5}\right)_{4}$ 时产物收率 较高, 为 $84 \%$. 此外, 该方法还仅限于选用具有供电子 基团的化合物作为原料.
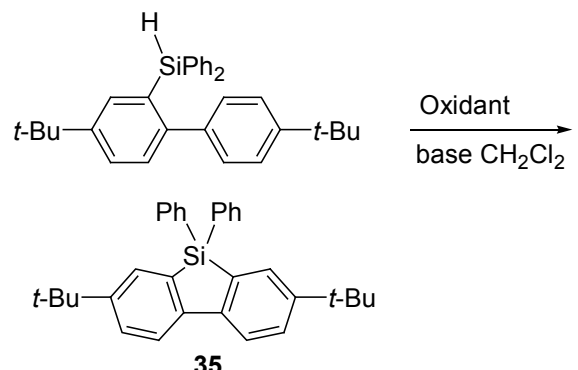

上述分子内硅-Friedel-Crafts 反应要求原料带有供 电基团，但当以带吸电基团化合物作为原料进行反应 时, 在金属铑催化下, 反应机理就不再是 Friedel-Crafts 反应, 而是金属铑催化 $\mathrm{Si}-\mathrm{H}$ 键和 $\mathrm{C}-\mathrm{H}$ 键双活化脱氢 反应. 以二联苯取代二甲基硅烷为起始原料, 在 1,4-二 氧六环中, 以 $\mathrm{RhCl}\left(\mathrm{PPh}_{3}\right)_{3}$ 为催化剂, 可得 1,1-二甲基二 苯并噻咯(36), 收率 $93 \%$. 具体过程见 Eq. $7^{[84]}$. 此反应 用过渡金属铑配合物作为催化剂来活化 $\mathrm{Si}-\mathrm{H}$ 键和 $\mathrm{C}-\mathrm{H}$ 键, 其中苯环上 $\mathrm{C}-\mathrm{H}$ 键活化是决定反应速率的 关键. 该反应不需要氧化剂, 反应时间短, 收率较高, 但同样原料来源受限.

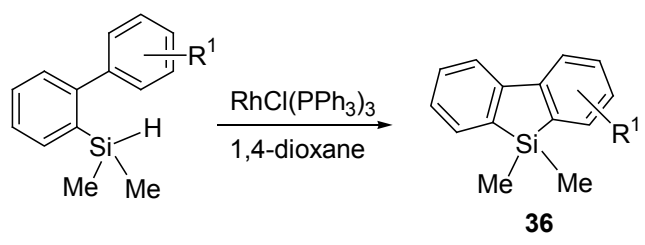

关于二苯并噻咯除了有关合成方法和结构修饰外, 还有学者对其性能进行了相关研究, 主要是从理论和实 验研究两个方面进行的.

首先是有关性能理论研究, 采用密度泛函理论对 9杂荡(荡 9 位碳原子被杂原子 $\mathrm{B}, \mathrm{Si}, \mathrm{Ge}, \mathrm{N}, \mathrm{P}, \mathrm{O}, \mathrm{S}$ 和 $\mathrm{Se}$ 取代得到的)类物质的结构、电子和光学性能进行研究, 从而揭示其结构与性能间关系. 结果发现: 这些物质均 具有高度芳香性和光电活性. 与二联苯相比, 杂原子的 引入使得两个苯环间键长缩短、键角减小, 这些分子多 具有较低 LUMO 能级, 可作为良好的电子传输材料 ${ }^{[85]}$.

Akhtaruzzaman 等 ${ }^{[86}$ 设计并合成四种有机供体一受 体染料, 包括 3 个基于二苯并噻咯分子 37 39 (YS01, YS02, YS03)和一个基于芴分子 $\mathbf{4 0}$ (YS04), 通过对它们 光物理和染料敏化太阳能电池性能的研究发现: 基于二
苯并噻咯染料分子的光电转换效率优于基于芴的染料 分子. YS03 具有较多较大供电基团，具有较强光捕获能 力, 阻止了染料的聚集, 进而使得它具有较高总转化效 率，达 5.07\%, 而 YS04 仅为 $2.88 \%$. 采用密度泛函理论 在 DGDZVP 基组上研究了这几个分子的平衡分子几何 构型, 发现 YS01 YS03 中联苯间扭转角比 YS04 小, 使得它们 $\pi-\pi$ *跃迁增强, 从而增强了光与电流间的转 化. 研究表明，按照上述思路可设计得到含硅有机染料 分子, 有望作为染料敏化太阳能电池全色敏化剂. 该方 法为进一步设计获得敏化太阳能电池有机染料提供了 指导.

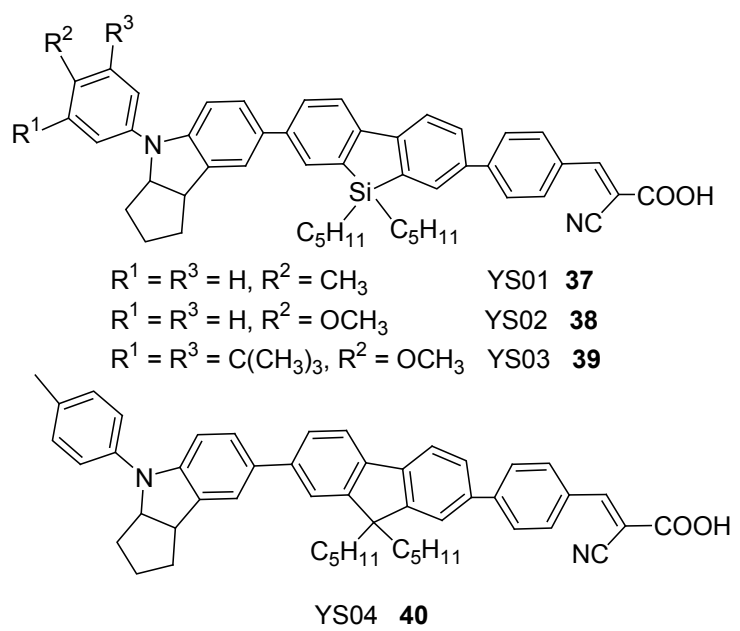

通过对 20 种硅芴和螺硅芴衍生物电子吸收光谱、 二阶极化率和重组能的研究 ${ }^{[87]}$, 结果发现：随着取代基 数量增加, 二阶极化率 $(\beta)$ 也相应增加, 重组能 $(\lambda)$ 则随之 减小. 3,6 位取代化合物二阶极化率和重组能比 2,7 位高. 供体/受体取代基可调节其电子传输性能，受体取代基 可大幅降低分子重组能. 因此增加取代基数目和吸电取 代基能够明显增强这类物质的性能. 电子吸收光谱研究 表明: 这些分子均符合非线性光学(NLO)透明度, 具有 较大二阶极化率 $(\beta)$ 、较小重组能 $(\lambda)$ 和优良光学透明度等 性能，因此这些化合物有望成为优良的二级非线性光学 (NLO)材料或电子传输材料.

二苯并噻咯类物质性能的有关理论研究有助于我 们从结构与性能关系角度来了解这些物质的性能, 在此 基础上，一些学者还对此类物质性能进行了相关实验研 究. 例如: 7,7'位有不同取代 9,9'-螺-9-硅二芴(SSF)衍生 物(41), 可形成透明的非晶体膜, 它们稳定性较好, 而 且具有相对较高玻璃转化温度 $\left(T_{g}=203 \sim 228{ }^{\circ} \mathrm{C}\right)$. 由于 分子中低聚亚芳基部分 $\pi$ *轨道和环外 $\mathrm{Si}-\mathrm{C}$ 键的 $\sigma *$ 轨 道间形成了有效 $\sigma^{*}-\pi^{*}$ 共轭, 其吸收光谱比相应碳类似 物明显向长波方向移动，它们所形成固态膜也具有强烈 紫蓝光发射 $\left(\lambda_{\mathrm{PL}}=398 \sim 415 \mathrm{~nm}\right)$ 和较高绝对光致发光量 子收率 $(30 \% \sim 55 \%)$. 研究表明这类物质有作为 OLED 
和固态激光器发光材料 ${ }^{[88]}$ 的潜在价值.

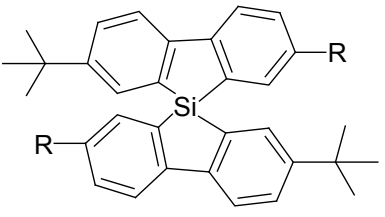

41

Yabusaki 等 ${ }^{[81]}$ 不仅合成得到了不同二苯并噻咯衍 生物, 而且还对此类物质的紫外可见吸收光谱和苂光光 谱进行了研究. 这些硅芴衍生物在 $290 \sim 340 \mathrm{~nm}$ 范围内 产生吸收, 在 $350 \sim 410 \mathrm{~nm}$ 范围内有荧光现象, 在 $450 \sim 650 \mathrm{~nm}$ 范围内能够产生较长时间的磷光现象, 磷 光量子效率较低, 但其中某些衍生物磷光量子效率比四 苯基硅烷高. 研究发现取代基不仅对二苯并噻咯吸收光 谱有影响, 还对它们的苂光和磷光量子效率有影响. 含 中性或供电子基团的二苯并噻咯量子效率比吸电基取 代二苯并噻咯高. 尤其是当 $R=P h, R^{1}=R^{4}=C O O M e$, $R^{2}=R^{3}=H$ 时, 该物质因具有 $J$ 型聚集结构, 从而具有 较高固态荧光效率. 在溶液状态, 它在 $351 \mathrm{~nm}$ 处产生发 射, 而在结晶状态下发射峰波长移动至 $392 \mathrm{~nm}$, 量子效 率也随之增加 ${ }^{[89]}$.

二苯并噻咯衍生物 $\mathbf{3 5}$ 的吸收峰位于 230 和 $297 \mathrm{~nm}$, 在二氯甲烷溶液中其在发射峰 $362 \mathrm{~nm}$ 处荧光量子效率 为 0.18 , 呈现强烈蓝色荧光. 同样在固体状态下, 其发 射峰位于 $361 \mathrm{~nm}$, 荧光量子效率为 $0.24^{[83]}$.

通过对二苯并噻咯类物质合成方法、结构修饰和相 关性能研究报道的分析可见目前还有许多需要完善的 地方. 例如: 有关该类物质的合成主要有四种方法, 还 很有限. 其中, 有些对反应操作条件要求较为苛刻; 有 些对原料结构如取代基类型等要求严格, 很多反应的原 料需要经过多步反应才能制得. 因此探寻反应条件温 和、操作简单，原料价廉易得、来源广泛的更加普遍适 用的合成方法是今后需要继续努力的研究方向. 同时有 关性能的报道也不多, 且多局限于光电性能研究方面, 因此有关耐高温高分子材料等方面的研究工作应该加 强. 特别是几乎没有关于应用的研究报道, 因此迫切需 要更加深入地研究这类物质的光电性能, 将其应用于光 电器件等方面, 同时还应该大力拓展其在耐高温高分子 材料等方面的应用研究.

\section{5 双硅桥联对-三联苯}

双硅桥联对一三联苯的结构如 $\mathbf{4 2}$ 所示, 该类衍生物 首次由 Murakami 等 ${ }^{[79]}$ 合成得到. 目前有关合成方法主 要包括铱催化双 $[2+2+2]$ 环加成、四锂化-双硅环化、 分子内硅-Friedel-Crafts 反应和金属铑催化 $\mathrm{Si}-\mathrm{H}$ 键和 $\mathrm{C}-\mathrm{H}$ 键双活化脱氢反应. 分别概述如下:

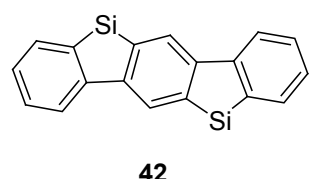

Murakami 等 ${ }^{[79]}$ 以双硅桥联四炔为原料，在过渡金 属铱催化下，与 1,4-二甲氧基-丁二炔通过双 [2+2+2] 环加成反应, 得到 $\mathbf{4 3}$ 所示化合物, 过程如 Eq. 8 所示. 该反应原料双硅桥联四炔可以采用 1,4 -二 溴-2,5-二碘苯为原料, 引入两个炔基后再与卤代硅烷反 应引入双硅桥, 然后再引入两个炔基后制得. 故该反应 可用于合成苯环上有多种、多个取代基的双硅桥联对三联苯衍生物. 该反应收率为 $58 \%$ ，与分子 $\mathbf{3 2}$ 相比较, 合成所得梯形分子 43 的吸收和发射峰均向长波方向移 动, 在发射峰 $396 \mathrm{~nm}$ 处, 分子 43 的苂光量子效率高达 0.91 .
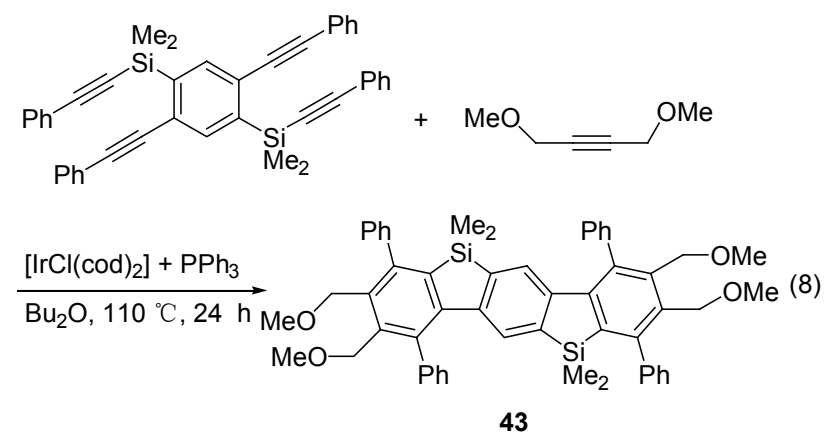

双硅桥联对一三联苯衍生物的合成除了采用双硅桥 联四炔作为原料之外，还可以采用不同取代对-三联苯 作为原料进行反应. 如 Eq. 9 所示, $\mathrm{Xu}$ 等 ${ }^{[00]}$ 以 2,2',5',2"四溴-对-三联苯为原料，与正丁基锂反应后，再与含不 同取代基二氯硅烷经过双硅环化反应得到含噻咯三联 苯衍生物. 该反应关键是原料 $2,2^{\prime}, 5^{\prime}, 2^{\prime}$-四溴-对-三联苯 的制备，但该原料合成步骤多，总收率低; 该四锂化一双 硅环化反应需要耗费大量有机锂试剂, 操作条件苛刻, 二氯硅烷所连接取代基类型对反应收率也有影响. 由于 原料的限制，该反应不适于合成苯环上具有多个取代基 的双硅桥联对-三联苯. 与相应碳桥联对-三联苯相比, 反应所得双硅桥联对-三联苯在 322 334 nm 范围内均 产生吸收, 波长无明显移动, 而发射峰则向长波方向移 动约 $20 \mathrm{~nm}$ 以上. 这说明硅原子的引入对吸收峰几乎没 有影响, 对发射峰的影响则较大. 这与硅桥联对二苯乙 烯衍生物中硅原子的引入使其吸收峰和发射峰均向长 波方向移动 ${ }^{[67]}$ 有所不同. 它们的荧光效率和相应碳桥 联对-三联苯相当, 这与梯形 $\pi$-电子体系中引入硅对其 量子效率影响不大 ${ }^{[16]}$ 的结论是一致的.

Furukawa 课题组 ${ }^{[82,83]}$ 以 2,2"-双(二苯基硅烷基)4,4"-二正丁基-对-三联苯为原料, 在二氯甲烷溶剂中, 


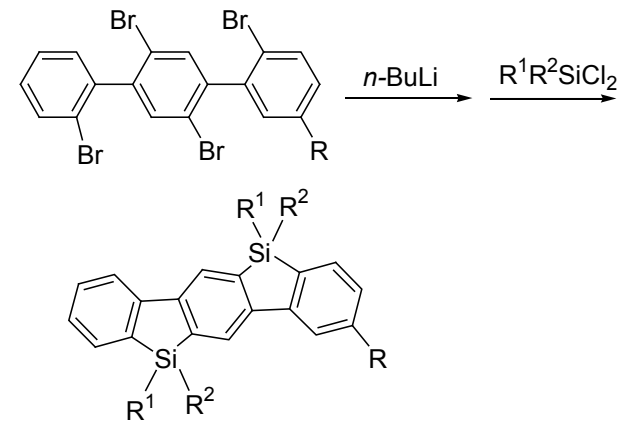

(9)

碱性条件下与氧化剂通过分子内硅-Friedel-Crafts 反应, 合成得到了双硅桥联对-三联苯衍生物(44), 过程如 Eq. 10 所示. 但是该反应收率仅为 $34 \%$, 且该反应对氧化 剂、碱和溶剂的类型都有一定要求.

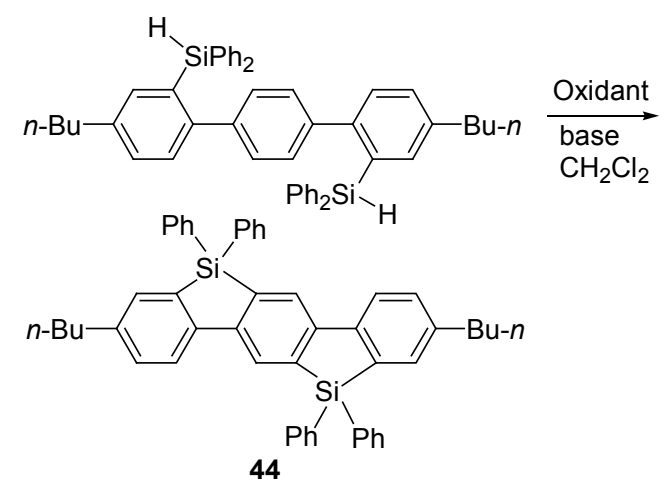

通过研究 44 的吸收和荧光光谱, 结果发现：与相应 二苯并噻咯衍生物即 35 相比较, 双硅桥联对-三联苯 44 的吸收峰和苂光峰均向长波方向发生了移动, 这是由 $\pi-$ 共轭的延伸引起的 HOMO-LUMO 能隙变窄所导致. 在 二氯甲烷溶液中, 44 的发射峰位于 $400,410 \mathrm{~nm}$ 处, 苂光 量子效率为 0.43 , 呈现出强烈蓝色荧光. 同样在固体状 态下，其发射峰位于 $419 \mathrm{~nm}$ 处，荧光量子效率为 0.66 , 也可以观察到蓝色荧光现象 ${ }^{[83]}$, 这表明其有望作为有 机蓝光苂光材料加以利用.

当以 2,2'-双(二甲基硅基)-对-三联苯为原料，在 1,4二氧六环溶剂中, 以 $\mathrm{RhCl}\left(\mathrm{PPh}_{3}\right)_{3}$ 为催化剂, 反应得到含 噻咯三联苯衍生物 45, 过程如 Eq. 11 所示 ${ }^{[84]}$. 此反应采 用过渡金属铑复合物作为催化剂来活化 $\mathrm{Si}-\mathrm{H}$ 键和 $\mathrm{C}-$ $\mathrm{H}$ 键, 脱氢后得梯形双硅桥联对-三联苯, 其中苯环上 $\mathrm{C}-\mathrm{H}$ 键的活化是决定反应速率的关键步骤, 而且脱氢 反应不需要氧化剂, 本反应三联苯收率高, 所产生副产 物仅有氢气，因此高效，清洁.

基于此方法，当采用二甲基(2-菜基)苯基硅烷作为 原料时, 可以得到硅桥联荟联苯(46)所示, 这是关于硅 桥联并苯联苯目前仅有的报道.

截止到目前, 关于双硅桥联对-三联苯衍生物的研 究报道还很少, 这类物质的合成方法还比较有限, 而且 反应收率不高, 原料多局限于对-三联苯类和双硅桥联
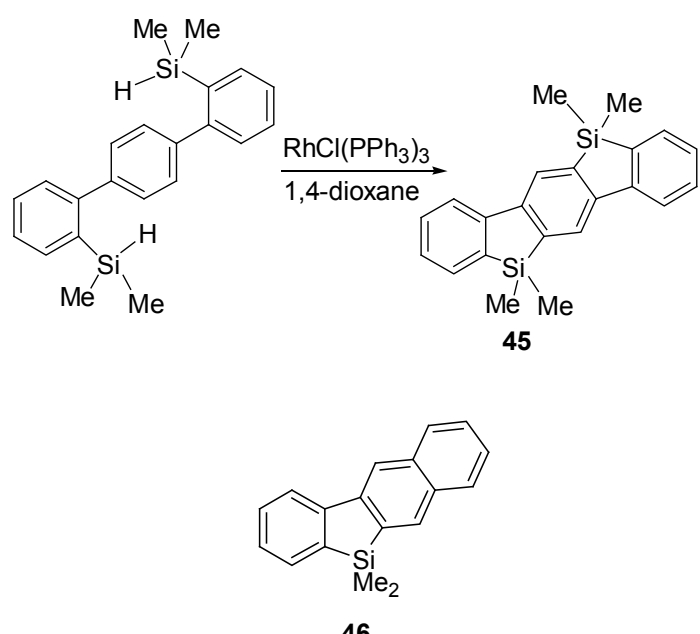

46

四炔类衍生物. 同时无论是与苯环相连的双硅桥联四炔 类物质还是卤素或硅烷取代的对-三联苯类化合物，均 需要经过多步反应才能合成得到, 较为繁琐, 以它们为 原料的研究报道较少. 因此, 选用价廉易得、来源广泛 的原料，寻找简便的原料合成途径，研究新的高效的合 成方法, 合成新型结构化合物等工作仍是今后值得我们 努力的方向. 同时关于这类物质结构与性能关系的研究 还不够深入，基本未见将这类材料应用于器件方面的研 究报道. 所以，同时也需要深入研究这类物质潜在的性 能, 开展将它们作为光电材料应用于器件等方面的研 究.

\section{6 结论与展望}

硅杂环戍二烯并苯有机小分子电子结构的特殊性, 使其具有独特光物理和电性能, 在有机光电功能材料等 领域有着广阔应用前景, 引起研究者广泛关注. 但至今 关于硅杂环戍二烯并苯有机小分子特别是硅桥联并苯 联苯的研究报道较少，这类物质现有合成方法也较有 限, 且存在一定局限性, 如原料不易获得、操作条件苛 刻和收率低等，因而限制了其广泛应用。另一方面，有 关此类物质结构与性能关系的研究还不够深入，基于这 些分子的材料应用于器件的研究报道较少, 主要是噻咯 类物质应用于发光二极管方面的研究报道, 其他硅桥联 并苯特别是双硅桥联对-三联苯等都很少见到关于其应 用的研究报道. 对于硅桥联并苯联苯分子的研究还不够 深入，目前仅有向噻咯一侧并入苯、一侧并入菜的研究， 尚末见一侧并入萗环、一侧并入葱环以及噻咯两侧并入 多并苯的报道. 因此, 有必要对硅杂环戊二烯并苯有机 小分子进行深入研究，探索原料价廉易得、选择性和收 率更高、操作条件更温和简便、新型普适的合成方法; 同 时优化现有反应条件, 进一步进行有关结构修饰，以获 得更多具有所期望优良性能新型硅桥联并苯联苯 $\pi$-共 
轭化合物; 进一步研究相关性能, 探究硅桥对其性能的 影响及结构与性能之间的关系，通过分子设计与修饰， 调控目标分子性能, 进而设计合成新型硅杂环戊二烯并 苯有机小分子. 特别是关于这些物质应用的研究需要大 力加强, 在深入研究噻咯在太阳能电池、场效应晶体管 等方面应用的同时, 更应该开拓和开展其他几类硅桥联 并苯联苯体系的应用研究, 不应局限于光电器件领域, 还应该拓宽至其它诸如化学传感器、分子检测器等方面, 推动该类化合物在这些领域的应用与发展，这些工作都 仍有待于人们的进一步研究与探索.

\section{References}

[1] Katz, H. E.; Bao, Z. N.; Gilat, S. L. Acc. Chem. Res. 2001, 34, 359.

[2] Mas-Torrent, M.; Rovira, C. Chem. Soc. Rev. 2008, 37, 613.

[3] Usta, H.; Risko, C.; Wang, Z. M.; Huang, H.; Deliomeroglu, M. K.; Zhukhovitskiy, A.; Facchetti, A.; Marks, T. J. J. Am. Chem. Soc. 2009, 131, 5586.

[4] Mas-Torrent, M.; Rovira, C. Chem. Rev. 2011, 111, 4833.

[5] Palilis, L. C.; Murata, H.; Uchida, M.; Kafafi, Z. H. Org. Electron. 2003, 4, 113.

[6] Zhu, X. H.; Peng, J. B.; Cao, Y.; Roncali, J. Chem. Soc. Rev. 2011, 40, 3509 .

[7] Yokoyama, D. J. Mater. Chem. 2011, 21, 19187.

[8] Kwon, J. E.; Park, S. Y. Adv. Mater. 2011, 23, 3615.

[9] Cheng, Y. J.; Yang, S. H.; Hsu, C. S. Chem. Rev. 2009, 109, 5868.

[10] Hains, A. W.; Liang, Z. Q.; Woodhouse, M. A.; Gregg, B. A. Chem. Rev. 2010, 110, 6689.

[11] Li, C.; Liu, M. Y.; Pschirer, N. G.; Baumgarten, M.; Müllen, K. Chem. Rev. 2010, 110, 6817.

[12] Mouri, K.; Wakamiya, A.; Yamada, H.; Kajiwara, T.; Yamaguchi, S. Org. Lett. 2007, 9, 93.

[13] Bendikov, M.; Wudl, F.; Perepichka, D. F. Chem. Rev. 2004, 104, 4891.

[14] Wakim, S.; Bouchard, J.; Blouin, N.; Michaud, A.; Leclerc, M. Org. Lett. 2004, 6, 3413.

[15] Jacob, J.; Sax, S.; Piok, T.; List, E. J. W.; Grimsdale, A. C.; Mllen, K. J. Am. Chem. Soc. 2004, 126, 6987.

[16] Yamaguchi, S.; Xu, C. H.; Yamada, H.; Wakamiya, A. J. Organomet. Chem. 2005, 690, 5365.

[17] Lin, Y. Y.; Gundlach, D. J.; Nelson, S. F.; Jackson, T. N. IEEE Trans. Electron Devices 1997, 44, 1325.

[18] Yoo, S.; Domercq, B.; Kippelen, B. Appl. Phys. Lett. 2004, 85, 5427.

[19] Tamao, K.; Uchida, M.; Izumizawa, T.; Furukawa, K.; Yamaguchi, S. J. Am. Chem. Soc. 1996, 118, 11974.

[20] Yamaguchi, S; Tamao, K. J. Chem. Soc., Dalton Trans. 1998, 22 , 3693.

[21] Zhan, X. W.; Risko, C.; Amy, F.; Chan, C.; Zhao, W.; Barlow, S.; Kahn, A.; Brédas, J. L.; Marder, S. R. J. Am. Chem. Soc. 2005, 127, 9021.

[22] Bozeman, T. C.; Edwards, K. A.; Fecteau, K. M.; Verde Jr., M. G.; Blanchard, A.; Woodall, D. L.; Benfaremo, N.; Ford, J. R.; Mullin, J. L.; Prudente, C. K.; Tracy, H. J. J. Inorg. Organomet. Polym. 2011, 21, 316

[23] Murata, H.; Malliaras, G. G.; Uchida, M.; Shen, Y.; Kafafi, Z. H. Chem. Phys. Lett. 2001, 339, 161.

[24] Luo, J. D.; Xie, Z. L.; Lam, J. W.Y.; Cheng, L.; Chen, H. Y.; Qiu, C. F.; Kwok, H. S.; Zhan, X. W.; Liu, Y. Q.; Zhu, D. B.; Tang, B.
Z. Chem. Commun. 2001, 18, 1740.

[25] Li, L.-C.; Li, S.-H.; Xu, C.-H. Chemistry 2008, (1), 3 (in Chinese). (李良春，李书宏，徐彩虹，化学通报, 2008, (1), 3.)

[26] Fu, H. Y.; Cheng, Y. R. Curr. Org. Chem. 2012, 16, 1423.

[27] Corey, J. Y. Adv. Organomet. Chem. 2011, 59, 181.

[28] Braye, E. H.; Hübel, W. Chem. Ind. (London) 1959, 1250.

[29] Zhang, L.-H.; Yu, Q.-C.; Wan, J.-H. Prog. Chem. 2013, 25, 752 (in Chinese).

(张力红, 于庆才, 万俊华, 化学进展, 2013, 25, 752.)

[30] Kularatne, R. S.; Magurudeniya, H. D.; Sista, P. S.; Biewer, M. C.; Stefan, M. C. J. Polym. Sci., Polym. Chem. 2013, 51, 743.

[31] Liu, Z.-T.; Hu, Z.; Shen, Z.; Hu, S.-Q.; Wang, Z.-X.; Qi, X. Prog. Chem. 2012, 24, 377 (in Chinese).

(刘治田, 胡钊, 沈陟, 胡双强, 王子兴, 戚欣, 化学进展, 2012, 24, 377.)

[32] Qin, A. J.; Lam, J. W. Y.; Tang, B. Z. Prog. Ploym. Sci. 2012, 37, 182.

[33] Chen, J. W.; Cao, Y.; Tang, B. Z. In Macromolecules Containing Metal and Metal-Like Elements, Vol. 10, Eds.: Abd-El-Aziz, A. S.; Carraher, C. E.; Pittman, C. U.; Sheats, J. E.; Zeldin, M., Wiley-Interscience, 2010, pp. 191 204.

[34] Chen, J. W.; Cao, Y. In Design and Synthesis of Conjugated Polymers, Eds.: Mario, L.; Jean-Francois, M., Wiley-VCH Verlag GmbH \& Co. KGaA, Weinheim, Germany, 2010, pp. 247 285 .

[35] Wong, W. Y.; Harvey, P. D. Macromol. Rapid Commun. 2010, 31, 671.

[36] Howell, B. A.; Cho, Y. J. In 20th Annual Conference on Recent Advances in Flame Retardancy of Polymeric Materials, Ed.: Menachem, L., Stamford, Connecticut, USA, 2009, pp. 120 131.

[37] Chen, J. W.; Cao, Y. Acc. Chem. Res. 2009, 42, 1709.

[38] Sanchez, J. C.; Trogler, W. C. Macromol. Chem. Phys. 2008, 209, 1527.

[39] Corey, J. Y. Adv. Organomet.Chem. 2011, 59, 1.

[40] Ohshita, J. Macromol. Chem. Phys. 2009, 210, 1360.

[41] Liu, J. Z.; Lam, J. W. Y.; Tang, B. Z. J. Inorg. Organomet. Polym. 2009, 19, 249.

[42] Abd Rabo Moustafa, M. M.; Pagenkopf, B. L. C. R. Chim. 2009, 12,359 .

[43] Qian, L.-J.; Zhi, J.-G.; Tong, B.; Yang, F.; Zhao, W.; Dong, Y.-P. Prog. Chem. 2008, 20, 673 (in Chinese).

(钱立军, 支俊格, 佟斌, 杨帆, 赵玮, 董宇平, 化学进展, 2008, 20, 673.)

[44] Ohmura, T. Yuki Gosei Kagaku Kyokaishi 2013, 71, 804.

[45] Zhao, Z. J.; Lam, J. W. Y.; Tang, B. Z. Soft Matter 2013, 9, 4564.

[46] Tobisu, M.; Chatani, N. Shokubai 2011, 53, 266.

[47] Ma, Q.-Y.; Guan, R.-F.; Li, G.-Z.; Feng, S.-Y. Chin. J. Org. Chem. 2011, 31, 1395 (in Chinese) (马庆宇, 关瑞芳, 李国忠, 冯圣玉, 有机化学, 2011, 31, 1395.)

[48] Zhang, Y.-S.; Qin, J.-H.; Xu, C.-H. Silicone Mater. 2011, 25, 190 (in Chinese) (张运生, 秦九红, 徐彩虹, 有机硅材料, 2011, 25, 190.)

[49] Wang, M.; Zhang, G. X.; Zhang, D. Q.; Zhu, D. B.; Tang, B. Z. J. Mater. Chem. 2010, 20, 1858.

[50] Mao, L.-Y.; Wan, J.-H.; Li, Z.-F.; Tao, L.; Qiu, H.-Y. Prog. Chem. 2009, 21, 2153 (in Chinese).

(毛林燕, 万俊华, 李志芳, 陶兰, 邱化玉, 化学进展, 2009, 21, 2153.)

[51] Zhu, L.-H.; Xia, H.-P.; Ding, M.-T. J. Funct. Mater. 2005, 36, 169 (in Chinese). (朱林晖, 夏海平, 丁马太, 功能材料, 2005, 36, 169.)

[52] Zhu, L.-H.; Xia, H.-P.; Ding, M.-T. J. Funct. Mater. 2005, 36, 325 (in Chinese). 
(朱林晖, 夏海平, 丁马太, 功能材料, 2005, 36, 325.)

[53] Shu, W.-F.; Li, S.-S.; Wang, C.-Y.; Shen, Y.-J. Sciencepaper Online 2010, 5, 731 (in Chinese).

(束伟夫，李珊珊，王成云，沈永嘉，中国科技论文在线，2010，5， 731.)

[54] Wang, F.; Li, Y.-D.; Wang, L.; Chen, J.-W. J. Wuhan Inst. Tech. 2012, 34, 5 (in Chinese).

(汪锋, 李昱达, 汪否, 陈军武, 武汉工程大学学报, 2012, 34, 5.)

[55] Ye, A.-Y.; Yang, X.-L.; Zuo, Y.-H. Guangdong Chem. Ind. 2011, 38, 21 (in Chinese).

(叶爱英, 杨小林, 左银虎, 广东化工, 2011, 38, 21.)

[56] Ye, A.-Y.; Yang, X.-L.; Zuo, Y.-H. Appl. Chem. Ind. 2012, 41, 1579 (in Chinese).

(叶爱英, 杨小林, 左银虎, 应用化工, 2012, 41, 1579.)

[57] Tang, B. Z.; Zhan, X. W.; Yu, G.; Lee, P. P. S.; Liu, Y. Q.; Zhu, D. B. J. Mater. Chem. 2001, 11, 2974.

[58] Chen, J. W.; Law, C. C. W.; Lam, J. W. Y.; Dong, Y. P.; Lo, S. M. F.; Williams, I. D.; Zhu, D. B.; Tang, B. Z. Chem. Mater. 2003, 15, 1535.

[59] Chen, H. Y.; Lam, W. Y.; Luo, J. D.; Ho, Y. L.; Tang, B. Z.; Zhu, D. B.; Wong, M.; Kwok, H. S. Appl. Phys. Lett. 2002, 81, 574.

[60] Barton, T. J.; Groh, B. L. Organometallics 1985, 4, 575.

[61] Xu, C. H.; Wakamiya, A.; Yamaguchi, S. Org. Lett. 2004, 6, 3707.

[62] Shirakawa, E.; Masui, S.; Narui, R.; Watabe, R.; Ikeda, D.; Hayashi, T. Chem. Commun. 2011, 47, 9714.

[63] Matsuda, T.; Kadowaki, S.; Yamaguchi, Y.; Murakami, M. Chem. Commun. 2008, 24, 2744.

[64] Matsuda, T.; Yamaguchi, Y.; Shigeno, M.; Sato, S.; Murakami, M. Chem. Commun. 2011, 47, 8697.

[65] Kuznetsov, A.; Gevorgyan, V. Org. Lett. 2012, 14, 914.

[66] Ma, Z. X.; Ijadi-Maghsoodi, S.; Barton, T. J. Polym. Preprints 1997, 38, 249

[67] Yamaguchi, S.; Xu, C. H.; Tamao, K. J. Am. Chem. Soc. 2003, 125, 13662.

[68] Li, C. H.; Qiu, H. Y.; Xu, C. H. Chin. Chem. Lett. 2007, 18, 1436.

[69] Kan, Y. H.; Su, Z. M.; Yan, L. K.; Teng, Y. L.; Yang, S. Y.; Wang, R. S. Synth. Met. 2005, 152, 269.

[70] Yu, W. L.; Cao, Y.; Pei, J.; Huang, W.; Heeger, A. J. Appl. Phys. Lett. 1999, 75, 3270.

[71] Wu, W. S.; Inbasekaran, M.; Hudack, M.; Welsh, D.; Yu, W. L.; Cheng, Y.; Wang, C.; Kram, S.; Tacey, M.; Bernius, M.; Fletcher, R.; Kiszka, K.; Munger, S.; O'Brien, J. Microelectron. J. 2004, 35,
343.

[72] Yang, C.; Song, H. S.; Liu, D. B. J. Mater. Sci. 2013, 48, 6719.

[73] Gilman, H.; Gorsich, R. D. J. Am. Chem. Soc. 1955, 77, 6380.

[74] Chen, J. W.; Cao, Y. Macromol. Rapid Commun. 2007, 28, 1714.

[75] Beaupré, S.; Boudreault, P. L. T; Leclerc, M. Adv. Mater. 2010, 22, E6.

[76] Gilman, H.; Gorsich, R. D. J. Am. Chem. Soc. 1957, 80, 1883.

[77] Chan, K. L.; McKiernan, M. J.; Towns, C. R.; Holmes, A. B. J. Am. Chem. Soc. 2005, 127, 7662.

[78] Chen, R. F.; Fan, Q. L.; Zheng, C.; Huang, W. Org. Lett. 2006, 8, 203.

[79] Matsuda, T.; Kadowaki, S.; Goya, T.; Murakami, M. Org. Lett. 2007, 9, 133 .

[80] Shimizu, M.; Mochida, K.; Hiyama, T. Angew. Chem., Int. Ed. 2008, 47, 9760 .

[81] Yabusaki, Y.; Ohshima, N.; Kondo, H.; Kusamoto, T.; Yamanoi, Y.; Nishihara, H. Chem. Eur. J. 2010, 16, 5581.

[82] Furukawa, S.; Kobayashi, J.; Kawashima, T. J. Am. Chem. Soc. 2009, 131, 14192.

[83] Furukawa, S.; Kobayashi, J.; Kawashima, T. Dalton Trans. 2010, 39, 9329.

[84] Ureshino, T.; Yoshida, T.; Kuninobu, Y.; Takai, K. J. Am. Chem. Soc. 2010, 132, 14324.

[85] Chen, R. F.; Zheng, C.; Fan, Q. L.; Huang, W. J. Comput. Chem. 2007, 28, 2091.

[86] Akhtaruzzaman, M.; Seya, Y.; Asao, N.; Islam, A.; Kwon, E.; El-Shafei, A.; Han, L. Y.; Yamamoto, Y. J. Mater. Chem. 2012, 22, 10771.

[87] Si, Y. L.; Yang, G. C. Theor. Chem. Acc. 2011, 128, 249.

[88] Lee, S. H.; Jang, B. B.; Kafafi, Z. H. J. Am. Chem. Soc. 2005, 127, 9071.

[89] For reports on the redshift of emission spectra and enhancement in emission yields in the solid state, see: (a) Davis, R.; Kumar, N. S. S.; Abraham, S.; Suresh, C. H.; Rath, N. P.; Tamaoki, N.; Das, S. J. Phys. Chem. C 2008, 112, 2137.

(b) Itami, K.; Ohashi, Y.; Yoshida, J. J. Org. Chem. 2005, 70, 2778.

(c) Ono, K.; Yoshikawa, K.;. Tsuji, Y.; Yamaguchi, H.; Uozumi, R.; Tomura, M.; Taga, K.; Saito, K. Tetrahedron 2007, 63, 9354.

(d) Ooyama, Y.; Nagano, S.; Okumura, M.; Yoshida, K. Eur. J. Org. Chem. 2008, 35, 5899.

[90] Li, L. C.; Xiang, J. F.; Xu, C. H. Org. Lett. 2007, 9, 4877. 